\title{
A multi-linear flow model for multistage fractured horizontal wells in shale reservoirs
}

\author{
Qi Zhang ${ }^{1} \cdot$ Yuliang Su${ }^{1} \cdot$ Min Zhang ${ }^{1} \cdot$ Wendong Wang ${ }^{1}$
}

Received: 7 April 2016/Accepted: 6 September 2016/Published online: 19 September 2016

(c) The Author(s) 2016. This article is published with open access at Springerlink.com

\begin{abstract}
This paper presents an analytical multi-linear flow model for shale gas reservoirs with multistage fractured horizontal wells (MFHW). It has been proved that the hydraulic fractures are branched rather than simple bi-wing shape, and the seepage flow of shale gas reservoirs is more complicated than conventional gas reservoirs due to the gas occurrence characteristics and fracture networks. Based on the published trilinear flow models, a developed five-region model considering effective fractured volume and adsorption effect was established. Laplace transformation method and Stehfest numerical algorithm were used to obtain typical pressure response curves. In addition, the presented model was validated by the actual production data, different flow regimes were divided, and the prediction of presented model was compared with the results of Eclipse simulator. Effects of some factors such as stimulated reservoir volume, storativity ratio, and Langmuir volume on the performance were analyzed. The results showed that the presented model considering stimulated volume and adsorbed gas could predict the productivity of MFHW better. The linear flow of stimulated region was the main contribution to gas production, and the duration of formation linear flow was influenced by different parameters. So the selection of optimal combination is very important in the development of shale gas reservoirs.
\end{abstract}

Keywords Shale gas reservoir - Adsorption and desorption . Multistage fractured horizontal well - Multi-linear flow model $\cdot$ Semi-analytical solution

Yuliang Su

zhangqi6242006@gmail.com

1 School of Petroleum Engineering, China University of Petroleum (East China), Qingdao, Shandong 266580, China

\section{Abbreviations}

$p \quad$ The gas pressure (MPa)

$\rho_{\mathrm{g}} \quad$ The shale gas density $\left(\mathrm{kg} / \mathrm{m}^{3}\right)$

$\rho_{\text {gsc }}$ The shale gas density in standard condition $\left(\mathrm{kg} / \mathrm{m}^{3}\right)$

$k \quad$ The permeability $\left(\mathrm{m}^{2}\right)$

$\phi \quad$ The porosity, fraction

$\mu \quad$ The gas viscosity $(\mathrm{mPa} / \mathrm{s})$

$p_{\mathrm{L}} \quad$ Langmuir pressure (MPa)

$V_{\mathrm{L}} \quad$ Langmuir volume $\left(\mathrm{m}^{3}\right)$

$V_{\mathrm{E}} \quad$ The volume of gas adsorbed per unit volume of the reservoir in equilibrium at pressure $p\left(\mathrm{~m}^{3} / \mathrm{m}^{3}\right)$

$Z$ The compressibility factor of shale gas, dimensionless

$M \quad$ The apparent molecular weight $(\mathrm{g} / \mathrm{mol})$

$R \quad$ The universal gas constant, $8.314 \mathrm{~J} /(\mathrm{mol} \mathrm{K})$

$T \quad$ The reservoir temperature (K)

$C_{\mathrm{D}} \quad$ The dimensionless wellbore storage coefficient

$m$ The pseudo-pressure (MPa/s)

$\eta \quad$ The pressure transitivity

$x \quad$ Reservoir size in $x$-direction (m)

$y \quad$ Reservoir size in $y$-direction (m)

$x_{\mathrm{f}} \quad$ The length of the hydraulic fracture $(\mathrm{m})$

$n_{\mathrm{F}} \quad$ The numbers of hydraulic fractures along a horizontal well

$s \quad$ Laplace transform parameter with respect to dimensionless time

\section{Subscript}

D Dimensionless

m Matrix

f Fracture

i Initial condition

\section{Superscript}

- Laplace transform 


\section{Introduction}

The rapid economic growth results in the increased demand of energy and development of shale gas reservoirs. Due to the extremely ultra-low permeability of the reservoirs, it is a great challenge to develop shale reservoir commercially. With technical innovation in the past decades, massive stimulation has been broadly applied into the field and proved effectively, especially the application of multistage fractured horizontal well (MFHW) achieves the commercial exploitation. However, modeling fluid flow in the complex fracture networks remains challenging (Ezulike and Dehghanpour 2014).

In many cases, a fracture propagation can create a branch pattern and a complex fracture networks around the hydraulic fractures (Ali Daneshy 2003), which were defined as stimulated reservoir volume (SRV) (Mayerhofer et al. 2010; Wang et al. 2014). The high conductivity of SRV makes liquids flow into the well easily and benefits the well production (Stalgorova and Mattar 2012a; Clarkson 2013). Most of shale gas reservoirs in Eagle ford, Barnett, and Marcellus (Suliman et al. 2013; Agboada and Ahmadi 2013; Mayerhofer et al. 2006) have obtained high production due to SRV. In addition, carbon-rich components lead to the existence of the adsorbed gas and free gas phase in the shale formations (Juan and Aquiles 2012). With the pressure dropping down, the adsorbed gas will desorb from the surface of matrix during the development process, which also has a significant influence on gas production and could not be ignored in mathematical models (Bumb and McKee 1988).

The production of MFHW in shale reservoirs is mainly affected by the fluids in matrix, in fracture network, and in hydraulic fractures. Brown et al. $(2009,2011)$ proposed the trilinear flow model to research the MFHW performance in unconventional gas reservoirs. In their model, pressure transient analysis was obtained. Considering the limited width of the simulated region, five-region model was defined to simulate the SRV to extend the trilinear model (Stalgorova and Mattar 2012b). Dehghanpour and Shirdel (2011) improved the Ozkan's dual-porosity model (Ozkan et al. 2010) to explain the unexpected high gas production in shale gas reservoirs based on the pseudo-steady model of Warren and Root (Warren and Root 1963). Then, equivalent flow model (Ketineni S and Ertekin 2012) was used to describe the SRV and solved the elliptical flow problem by Mathieu modified functions. Based on this model, $\mathrm{Su}$ et al. (2015) characterized the SRV using a circular region in shale gas reservoir and analyzed the pressure performance considering the SRV. In addition to the analytical models, there are some numerical models to simulate the seepage flow of MFHW in unconventional reservoirs (Mediros et al. 2007; Mayerhofer et al. 2006; Meyer and Bazan 2011). All these models have some drawbacks, such as the complex computational process, relationships of parameters, and difficult application, so the simplifications of the flow models have to be considered.

At present, few models can simulate the performance behavior including pressure and rate transient analysis (PTA and RTA) successfully for MFHW with SRV in shale gas reservoirs. Bumb and Mckee (1988) took the desorption compressibility into account for shale gas reservoirs. Then, based on this model, lots of work (Gerami et al. 2008; Guo et al. 2012) have been done for unconventional gas reservoirs. These studies mainly focused on vertical well or horizontal well and few about the MFHW. Although Ozkan et al. (2010) and Brown et al. (2009) developed a trilinear flow model to simplify the complex process and get good results in unconventional gas reservoirs, desorption and adsorption mechanism, which is the key mechanism of shale gas reservoirs, was ignored. Sang et al. (2014) presented a new mathematical model considering adsorption and desorption process, which made up the disadvantage of the trilinear flow model for MFHW in shale gas reservoirs. Zhang et al. (2015) then presented a numerical five-region model with multi-nonlinearity to study the production of shale gas, which was difficultly to solve. In this paper, we extended the linear flow model considering effective stimulated volume and adsorption effect to multistage fractured horizontal wells in shale gas reservoirs. The bottom-hole pressure and production formulas are established, and effects of several key parameters are analyzed. The duration of formation linear flow under different parameters is studied, which helps to understand the flow mechanism of multiple hydraulic fractures in shale gas reservoirs.

\section{Model description}

\section{Physical model and its assumptions}

The physical model of the MFHW with SRV reflects the complex interplay of flow among matrix, natural fractures, and hydraulic fractures and is shown in Fig. 1.

The reservoir has five regions (Stalgorova and Mattar 2012 b) including hydraulic fracture region, three unstimulated regions, and stimulated region, and the multi-linear flow model is shown in Fig. 2. The unstimulated regions are described as single porous mediums with low flow capacity, the stimulated region is described as a single porous medium with high flow capacity influenced by natural fractures, and the hydraulic fractures have finite conductivity. However, the properties of the unstimulated 
Fig. 1 Multistage fractured horizontal well with SRV. a Geology schematic of MFHW development. b Physical model in this paper

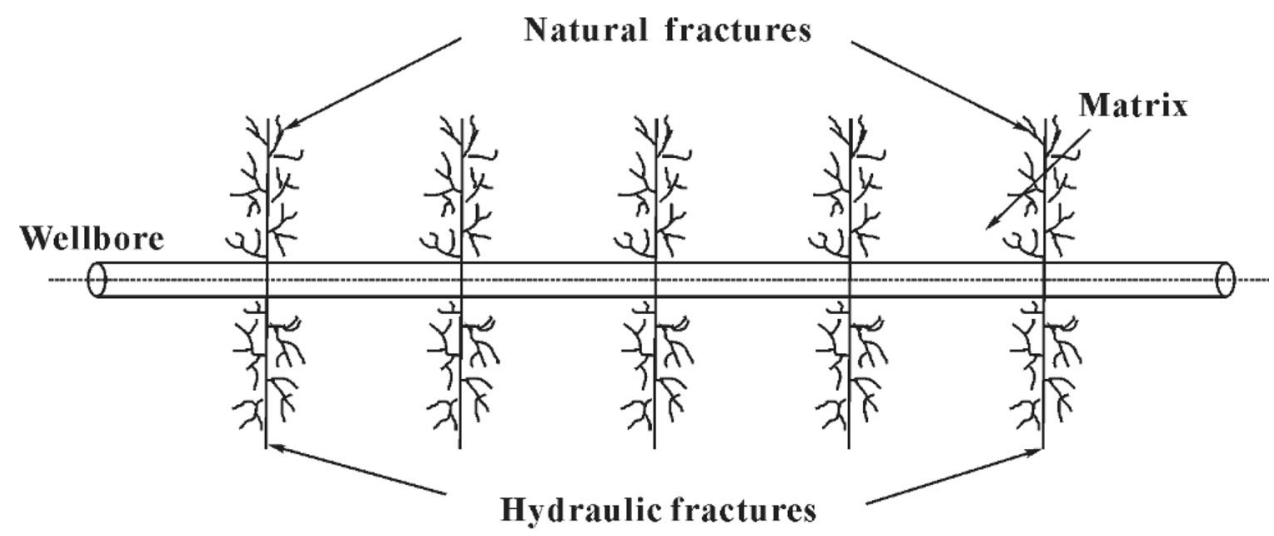

(a) Geology schematic of MFHW development

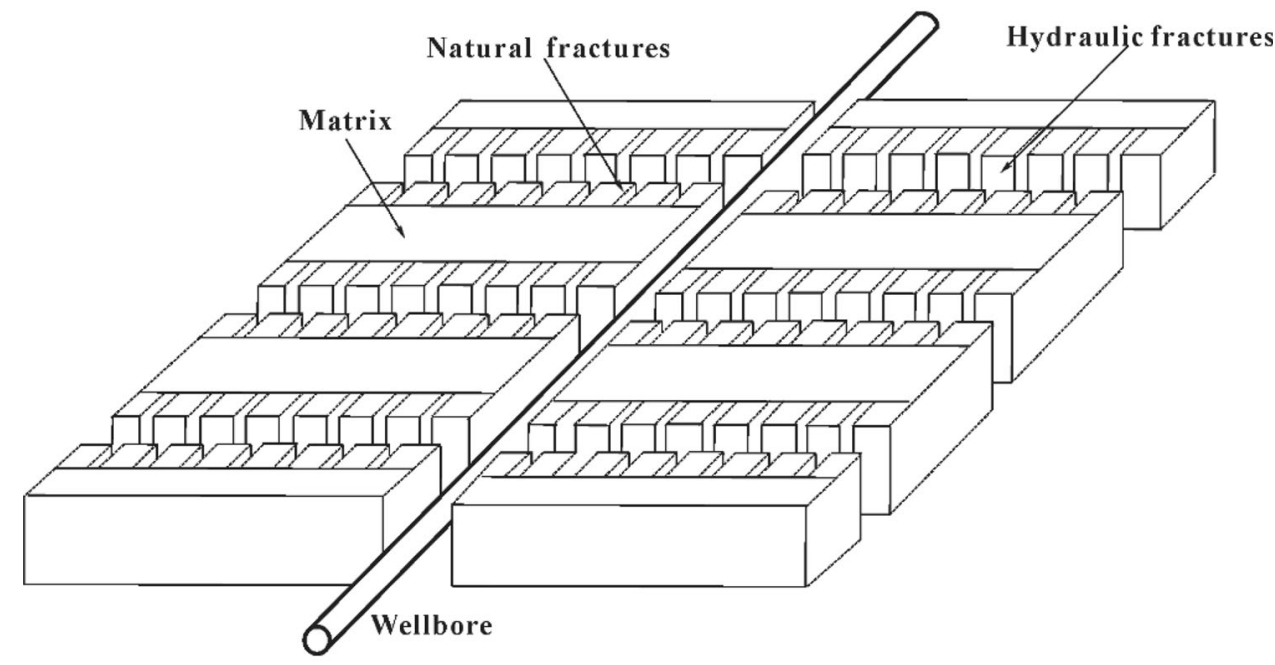

(b) Physical model in this paper

and stimulated regions are different in porosity, compressibility, and absorbability in the model, and adsorption-desorption process is taken into account. Some idealization and simplifying assumptions are as follows: (1) Single-phase gas of constant-compressibility fluid flows into the horizontal well from reservoir only by hydraulic fractures, and frictional loss within the horizontal well and effects of gravity and capillary forces are ignored in the reservoir. (2) The hydraulic fractures have identical properties and evenly distributed along the horizontal well. Hydraulic fractures can create high conductivity around the wellbore, which leads to higher permeability in stimulated region than unstimulated regions. (3) Gas desorption is instantaneous and follows Langmuir isotherm. The shale gas reservoir is isothermal. (4) There are the no-flow boundaries parallel to the hydraulic fractures at the middle of two fractures in closed reservoir. (5) Wellbore storage effect is taken into account. Flow in every region is assumed to be linear similar to the model proposed by Ozkan et al. (2010) and is shown in Fig. 2. This paper assumes that the stimulated region is a simple region to characterize the SRV. However, the SRV is very complex and cannot be described by regular shape in shale reservoirs. In addition, the stimulated region is assumed as a single porous medium with high permeability, which is not able to simulate the actual formation exactly. So it is necessary to research further in the future.

\section{Mathematical model}

Based on the above assumptions, combined with gas equation of state and mass balance equation, the presented multi-linear model is an extended five-linear flow model under the rectangular coordinate system. The detailed derivation process is shown in "Appendix."

- Liner flow in matrix

The gas in both the region 3 and the region 4 flows along the $y$-direction. Considering the adsorption and desorption process in these regions (Ross and Bustin 2007), mass conservation equations of the matrix flow can be written as 


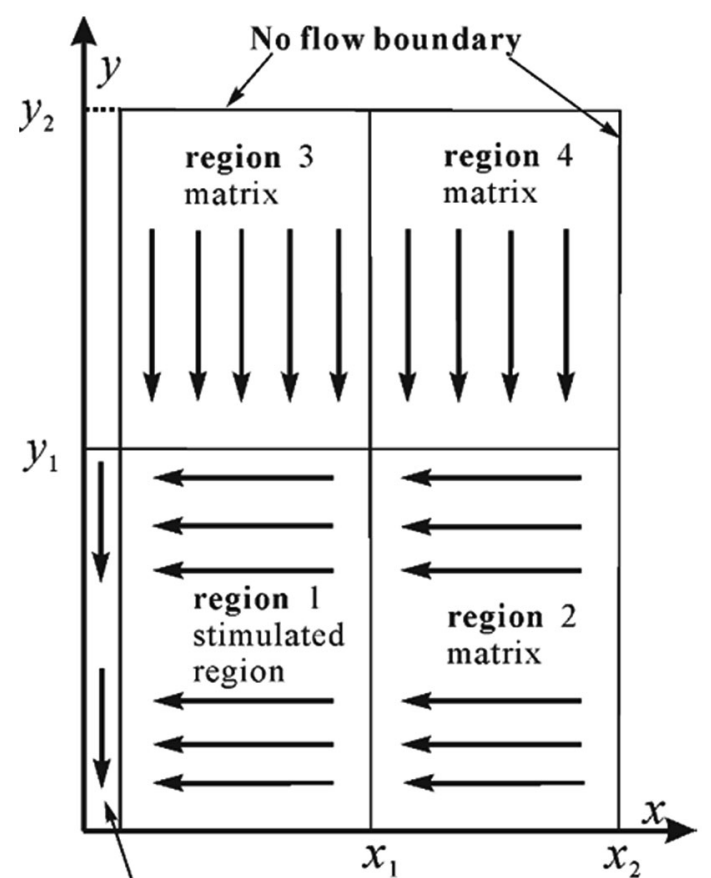

Hydraulic fracture region

Fig. 2 Multi-linear flow model (quarter of a fracture, Stalgorova and Mattar 2012a)

$k \frac{\partial}{\partial x}\left(\frac{2 p}{Z \mu} \frac{\partial p}{\partial x}\right)=\phi_{\mathrm{m}} \mu\left\{\left(\frac{1}{p}-\frac{1}{Z} \frac{\partial Z}{\partial p}\right)+\frac{\rho_{\mathrm{gsc}} V_{\mathrm{L}} p_{\mathrm{L}}}{\phi_{\mathrm{m}} \frac{M p}{Z R T}\left(p+p_{\mathrm{L}}\right)^{2}}\right\} \frac{2 p}{Z \mu} \frac{\partial p}{\partial t}$.

In the shale gas reservoir, define pseudo-pressure equation

$m=\int_{0}^{p} \frac{2 p}{Z \mu} \mathrm{d} p$,

According to the "Appendix," Eq. (1) becomes

$\frac{\partial^{2} m}{\partial x^{2}}=\frac{1}{\eta} \frac{\partial m}{\partial t}$

Using Laplace transform, combining with the initial condition and boundary conditions, the mathematical model of linear flow in the region 4 and the region 3 can be expressed as

$$
\left\{\begin{array}{l}
\frac{\partial^{2} \bar{m}_{n \mathrm{D}}}{\partial y_{\mathrm{D}}^{2}}-\frac{2}{\eta_{\mathrm{D}}} \bar{m}_{n \mathrm{D}}=0 \\
\left.\frac{\partial \bar{m}_{n \mathrm{D}}}{\partial y_{\mathrm{D}}}\right|_{y_{\mathrm{D}}=y_{2 \mathrm{D}}}=0 \\
\left.\bar{m}_{n \mathrm{D}}\right|_{y_{\mathrm{D}}=y_{1 \mathrm{D}}}=\left.\bar{m}_{(n-2) \mathrm{D}}\right|_{y_{\mathrm{D}}=y_{1 \mathrm{D}}}
\end{array} .\right.
$$

The solution of Eq. (4) in Laplace space is derived as

$\bar{m}_{n \mathrm{D}}=\left.\bar{m}_{(n-2) \mathrm{D}}\right|_{y_{\mathrm{D}}=y_{1 \mathrm{D}}} \times \frac{\cosh \left[\sqrt{r}\left(y_{2 \mathrm{D}}-y_{\mathrm{D}}\right)\right]}{\cosh \left[\sqrt{r}\left(y_{1 \mathrm{D}}-y_{2 \mathrm{D}}\right)\right]}$.

where $n=3,4, r=s / \eta_{\mathrm{D}}$.

In the region 2 , the adsorption-desorption process as well as the flux from the region 4 is taken into account.

Then, the mathematical model of region 2 in Laplace space is

$$
\left\{\begin{array}{l}
\frac{\partial^{2} \bar{m}_{2 \mathrm{D}}}{\partial x_{\mathrm{D}}^{2}}+\left.\frac{1}{y_{1 \mathrm{D}}} \frac{k_{4}}{k_{2}} \frac{\partial \bar{m}_{4 \mathrm{D}}}{\partial y_{\mathrm{D}}}\right|_{y_{\mathrm{D}}=y_{1 \mathrm{D}}}=\frac{s}{\eta_{2 \mathrm{D}}} \bar{m}_{2 \mathrm{D}} \\
\left.\frac{\partial \bar{m}_{2 D}}{\partial x_{D}}\right|_{x_{\mathrm{D}}=x_{2 \mathrm{D}}}=0 \\
\left.\bar{m}_{2 \mathrm{D}}\right|_{x_{\mathrm{D}}=x_{1 \mathrm{D}}}=\left.\bar{m}_{1 D}\right|_{x_{\mathrm{D}}=x_{1 \mathrm{D}}}
\end{array} .\right.
$$

The solution of Eq. (6) in Laplace space is

$$
\bar{m}_{2 \mathrm{D}}=\left.\bar{m}_{1 \mathrm{D}}\right|_{x_{\mathrm{D}}=x_{1 \mathrm{D}}} \times \frac{\cosh \left[\sqrt{a}\left(x_{\mathrm{D}}-x_{2 \mathrm{D}}\right)\right]}{\cosh \left[\sqrt{a}\left(x_{1 \mathrm{D}}-x_{2 \mathrm{D}}\right)\right]},
$$

where $a=\frac{1}{y_{1 D}} \frac{k_{4}}{k_{2}} \frac{\sqrt{r} \sinh \left[\sqrt{r}\left(y_{2 D}-y_{1 D}\right)\right]}{\cosh \left[\sqrt{r}\left(y_{1 D}-y_{2 D}\right)\right]}-\frac{s}{\eta_{2 D}}$.

- Linear flow in stimulated region

$\left\{\begin{array}{l}\frac{\partial^{2} \bar{m}_{1 \mathrm{D}}}{\partial x_{\mathrm{D}}^{2}}+\left.\frac{1}{y_{1 \mathrm{D}}} \frac{k_{3}}{k_{f 1}} \frac{\partial \bar{m}_{3 \mathrm{D}}}{\partial y_{\mathrm{D}}}\right|_{y_{\mathrm{D}}=y_{1 \mathrm{D}}}=\frac{s}{\eta_{\mathrm{f} 1 \mathrm{D}}} \bar{m}_{2 \mathrm{D}} \\ \left.k_{2} \frac{\partial \bar{m}_{2 \mathrm{D}}}{\partial x_{\mathrm{D}}}\right|_{x_{\mathrm{D}}=x_{1 \mathrm{D}}}=\left.k_{1} \frac{\partial \bar{m}_{1 \mathrm{D}}}{\partial x_{\mathrm{D}}}\right|_{x_{\mathrm{D}}=x_{1 \mathrm{D}}} \\ \left.\bar{m}_{1 D}\right|_{x_{\mathrm{D}}=w_{\mathrm{fD}} / 2}=\left.\bar{m}_{f D}\right|_{x_{\mathrm{D}}=w_{\mathrm{fD}} / 2}\end{array}\right.$.

The solution of Eq. (8) in Laplace space is

$\bar{m}_{1 \mathrm{D}}=\left.\mathrm{e}^{\sqrt{b} \frac{w_{\mathrm{fD}}}{2}} \bar{m}_{\mathrm{fD}}\right|_{x_{\mathrm{D}}=\frac{w_{\mathrm{fD}}}{2}}\left[\frac{(f+1) \mathrm{e}^{\sqrt{b} x_{\mathrm{D}}}+(1-f) \mathrm{e}^{2 \sqrt{b} x_{1 \mathrm{D}}-\sqrt{b} x_{\mathrm{D}}}}{\mathrm{e}^{2 \sqrt{b} x_{\mathrm{ID}}}+\mathrm{e}^{2 \sqrt{b} \frac{w_{\mathrm{fD}}}{2}}-\left(\mathrm{e}^{2 \sqrt{b} x_{1 \mathrm{D}}}-\mathrm{e}^{2 \sqrt{b} \frac{w_{\mathrm{fD}}}{2}}\right) f}\right]$,

- Linear flow in hydraulic fracture region

Through Laplace transformation, we can get the model set with no-flow tip of the fracture and constant production rate at the bottom hole:

$$
\left\{\begin{array}{l}
\frac{\partial^{2} \bar{m}_{\mathrm{fD}}}{\partial y_{\mathrm{D}}^{2}}+\left.\frac{2}{C_{\mathrm{FD}}} \frac{\partial \bar{m}_{1 \mathrm{D}}}{\partial y x_{\mathrm{D}}}\right|_{x_{\mathrm{D}}=w_{\mathrm{fD}} / 2}=s \bar{m}_{\mathrm{fD}} \\
\left.\frac{\partial \bar{m}_{\mathrm{fD}}}{\partial y_{\mathrm{D}}}\right|_{y_{\mathrm{D}}=y_{1 \mathrm{D}}}=0 \\
\left.\frac{\partial \bar{m}_{\mathrm{fD}}}{\partial y_{\mathrm{D}}}\right|_{y_{\mathrm{D}}=0}=-\frac{\pi}{s C_{\mathrm{FD}}}
\end{array}\right.
$$

When $y_{\mathrm{D}}=0$, the solution of bottom-hole pressure in Laplace space could be derived as 
$\bar{m}_{\mathrm{wD}}=\left.\bar{m}_{\mathrm{fD}}\right|_{y_{\mathrm{D}}=0}=\frac{\pi}{\sqrt{g} s C_{\mathrm{FD}}} \frac{1}{\tanh \left(-\sqrt{g} y_{1 \mathrm{D}}\right)}$.

According to Brown et al. (2009, 2011), storage effect could be taken into account with the following equation:

$\bar{m}_{\mathrm{wD}, \text { storage }}=\frac{\bar{m}_{\mathrm{wD}}}{1+C_{\mathrm{D}} s^{2} \bar{m}_{\mathrm{wD}}}$,

\section{Model solutions}

When the gas well working at a constant bottom-hole pressure, the relationship of dimensionless production rate and the dimensionless pressure could be deduced as follows (Everdingen and Hurst 1949)

$\bar{q}_{\mathrm{D}}=\frac{1}{s^{2} \bar{m}_{w \mathrm{D}}}$

Stehfest numerical inverse method (Stehfest 1970) is used to get the solution in real space.

$q\left(t_{\mathrm{D}}\right)=\frac{\ln 2}{t_{\mathrm{D}}} \sum_{i=1}^{N} V_{i} \bar{q}\left(\frac{\ln 2}{t_{\mathrm{D}}} i\right)$

where

$V_{\mathrm{i}}=(-1)^{N / 2}+\sum_{k=\left[\frac{i+1}{2}\right]}^{\min \left(\mathrm{i}, \frac{\mathrm{N}}{2}\right)} \frac{k^{N / 2}(2 k) !}{\left(\frac{N}{2}-k\right) ! k !(k-1) !(i-k) !(2 k-i) !}$.

With the assumption that the hydraulic fractures have the same properties, total production rate could be expressed as follows:

$Q\left(t_{\mathrm{D}}\right)=n_{\mathrm{F}} \times q\left(t_{\mathrm{D}}\right)$

\section{Model verification}

\section{Field example}

To confirm the application of the composite model of multistage fractured horizontal well in shale gas reservoirs presented in this paper, the actual data from one multistage fractured horizontal well in west China were used to verify the model. Fig. 3 represents the actual data compared with calculated production rate from modified five-region model [setting the flowing bottom-hole pressure (FBHP) to $4 \mathrm{MPa}$. The calculated values are significantly higher than the actual data, due to the complicated pressure condition in the initial stage of production and then the two curves fit well after a short time. If the adsorption and desorption process is not considered, the calculated values are lower than the values considering the adsorption and desorption process. Thus, the composite model could simulate the production performance of multistage fractured horizontal well considering the SRV and the adsorption and desorption process. The values of relevant parameters are listed as shown in Table 1.

\section{Comparison of the analytic model and Eclipse simulator}

Figure 4 shows the comparison of production rate between Eclipse simulator and the composite model. Although high production rate lasts short time, two curves have the similar tendency due to the free gas in the early stage of the production. With the development of the reservoir, the decreasing of pressure results that the natural adsorbed gas desorbs from the organic matrix and becomes an important part of the gas source. Therefore, the composite model demonstrates higher rate than the rate calculated by Eclipse simulator without considering the adsorption and desorption process. The conclusion can be drawn from Fig. 4 is that the adsorption and desorption process has a significant influence on the predict production and could not be neglected in the mathematical models. The desorption of adsorbed gas accounted for $20-55 \%$ of total production.

The free gas in fractures and inorganic matrix pores is produced first. Then, the absorbed gas on the organic matrix desorbs into the fractures gradually. Therefore, the production rate is relatively high in the first 2 years, which is above $10,000 \mathrm{~m}^{3} /$ day. There is a sharp decline, and the production rate remains a slower pace afterward. In addition, it is apparent that lower flowing bottom-hole pressure leads to larger drawdown pressure, which makes the production rate higher, such as the production rate under $p_{\mathrm{wf}}=4 \mathrm{MPa}$ is four times that under $p_{\mathrm{wf}}=16 \mathrm{MPa}$ at the corresponding time.

\section{Results and discussion}

\section{Analysis of type curve}

The type curve of the bottom-hole pressure and pressure derivative can be obtained using modified five-region model as shown in Fig. 5. According to the characteristic of pressure derivative profile, five flow regimes are classified.

As shown in Fig. 5, the type curve of MFHW considering SRV and adsorption and desorption process can be divided into the following eight regimes: (1) the early wellbore storage characterized by a slope of 1 in pressure and derivative curves. (2) the first transition flow stage between wellbore storage and the early linear flow. The dimensionless pressure curve and derivative curve are separate. (3) the dual-linear flow stage, which is 


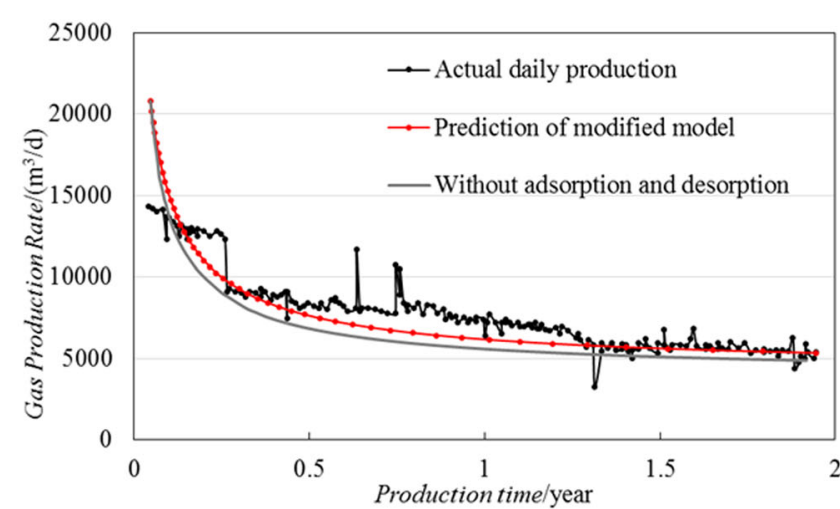

Fig. 3 Comparison of the actual data and calculated data of the well

Table 1 Shale reservoir and horizontal well parameters

\begin{tabular}{lll}
\hline Parameters & Unit & Value \\
\hline Matrix porosity, $\phi_{\mathrm{m}}$ & $\%$ & 8.0 \\
Fracture porosity, $\phi_{\mathrm{f} 1}$ & $\%$ & 0.6 \\
Hydraulic fracture porosity, $\phi_{\mathrm{f}}$ & $\%$ & 1.0 \\
Matrix compressibility, $c_{\mathrm{tm}}$ & $1 / \mathrm{MPa}$ & $2 \mathrm{e}-5$ \\
Fracture compressibility, $c_{\mathrm{tf} 1}$ & $1 / \mathrm{MPa}$ & $3.5 \mathrm{e}-4$ \\
Hydraulic fracture compressibility, $c_{\mathrm{tf}}$ & $1 / \mathrm{MPa}$ & $4.5 \mathrm{e}-4$ \\
Matrix permeability, $k_{\mathrm{m}}$ & $\mathrm{mD}$ & $1 \mathrm{e}-6$ \\
Fracture permeability, $k_{\mathrm{f} 1}$ & $\mathrm{mD}$ & $1 \mathrm{e}-3$ \\
Hydraulic fracture permeability, $k_{\mathrm{f}}$ & $\mathrm{mD}$ & 300 \\
Formation thickness, $h$ & $\mathrm{~m}$ & 46 \\
Horizontal section length, $L$ & $\mathrm{~m}$ & 1200 \\
Reservoir size in $y$-direction, $y_{2}$ & $\mathrm{~m}$ & 200 \\
Reservoir size in $x$-direction, $x_{2}$ & $\mathrm{~m}$ & 100 \\
Hydraulic fracture half-length, $x_{\mathrm{f}}$ & $\mathrm{m}$ & 75 \\
Hydraulic fracture width, $w_{\mathrm{f}}$ & $\mathrm{m}$ & 0.1 \\
Numbers of hydraulic fractures, $n_{\mathrm{F}}$ & - & 10 \\
Langmuir volume, $V_{\mathrm{L}}$ & $\mathrm{m}{ }^{3} / \mathrm{m}^{3}$ & 4 \\
Langmuir pressure, $P_{\mathrm{L}}$ & $\mathrm{MPa}$ & 12 \\
Well depth, $H$ & $\mathrm{~m}$ & 1500 \\
Initial reservoir pressure, $p_{\mathrm{i}}$ & $\mathrm{MPa}$ & 21 \\
Initial reservoir temperature, $T_{\mathrm{i}}$ & $\mathrm{K}$ & 338 \\
\hline
\end{tabular}

characterized by a slope of 0.25 in pressure derivative curve. (4) the linear flow stage of the formation. Pressure differential is proportional to the square root of dimensionless time, and the slope of pressure derivative in log$\log$ curve is 0.5 . (5) the adsorption and desorption process, which affects a depression in the pressure derivative curve. (6) the second transition flow stage between the linear flow in inner formation and outer formation. (7) the second linear flow stage of formation characterized by a slope of 0.5 in pressure derivative curve. With the influence of the non-flow boundary, the typical radial flow does not show on the graph. (8) The quasi-steady flow

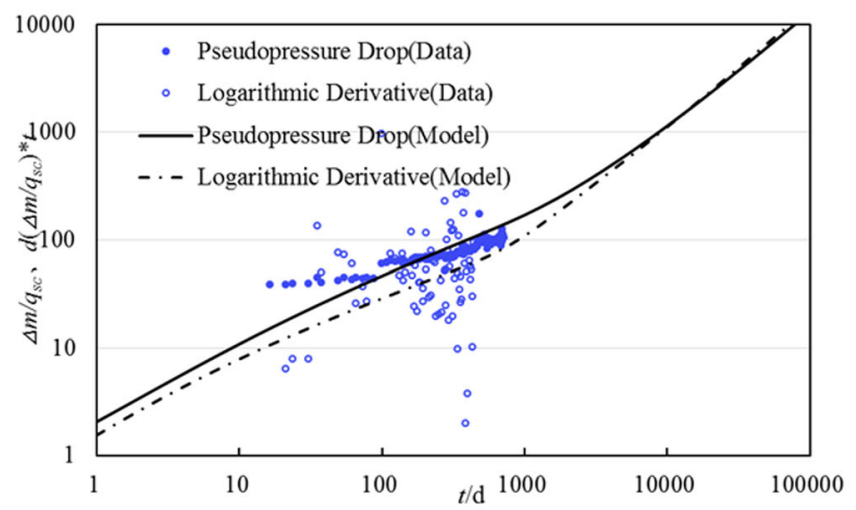

stage occurs in the last period when the whole system reaches steady state. Furthermore, the curves coincide again and go up together due to the non-flow boundary condition.

\section{Analysis of pressure transient responses}

Based on the values of relevant parameters listed, Fig. 6 could be obtained, where $C_{\mathrm{D}}=0,0.005,0.02,0.1$. This figure demonstrates the effect of dimensionless wellbore storage coefficient on pressure transient responses when the well produces at a constant production rate. When considering the wellbore storage coefficient (namely there is wellbore storage effect), there are different intercept with the same slope of 1 in $\log -\log$ plots of dimensionless pressure and pressure derivative curves. The wellbore storage coefficient results in the coincidence of two curves at the very beginning due to the production of the gas in the wellbore. Large wellbore storage coefficient means the wellbore storage effect is larger, which leads the joint part of the two curves is longer and even vanishes the next flow regimes. As the green line shows, there is no significant linear flow characteristics but adsorption and desorption process.

Figure 7 shows the variation in law of the pressure transient responses with changing values of Langmuir volume $\left(V_{\mathrm{L}}=0,3,5\right)$, and other values of relevant parameters listed in Table 1. Langmuir volume is associated with the ability of adsorption and desorption process in shale gas reservoirs. It is obvious that the Langmuir volume affects the (5)-(8) regimes significantly. The large value of Langmuir volume leads to the apparent depression in pressure derivative curve. In addition, the adsorption and desorption process can make up for the energy exhaustion. With the increase in the Langmuir volume, the downward movement of the dimensionless pressure curve and pressure derivative curve appears and the quasi-steady flow state appears later accordingly. 

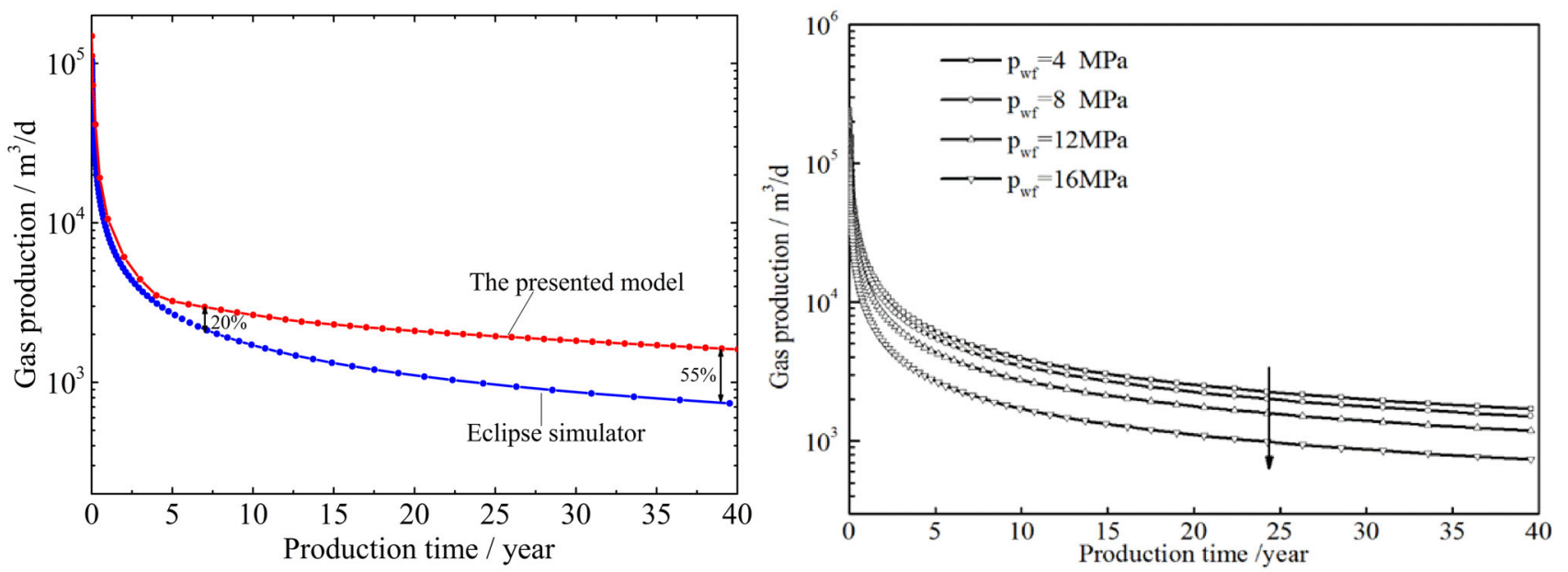

Fig. 4 Comparison of gas production from the Eclipse and the composite model with different FBHP

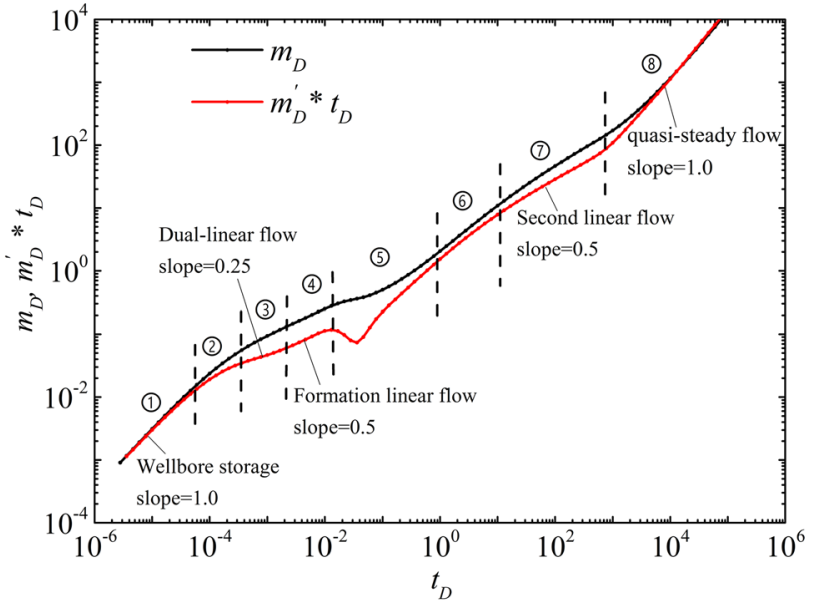

Fig. 5 Type curve of MFHW considering SRV and adsorption and desorption process

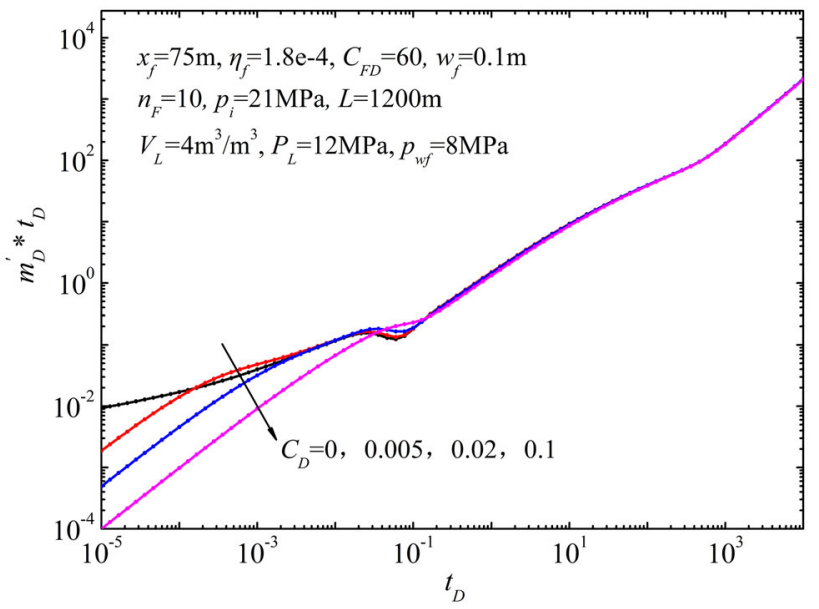

Fig. 6 Effect of dimensionless wellbore storage coefficient on pressure transient responses

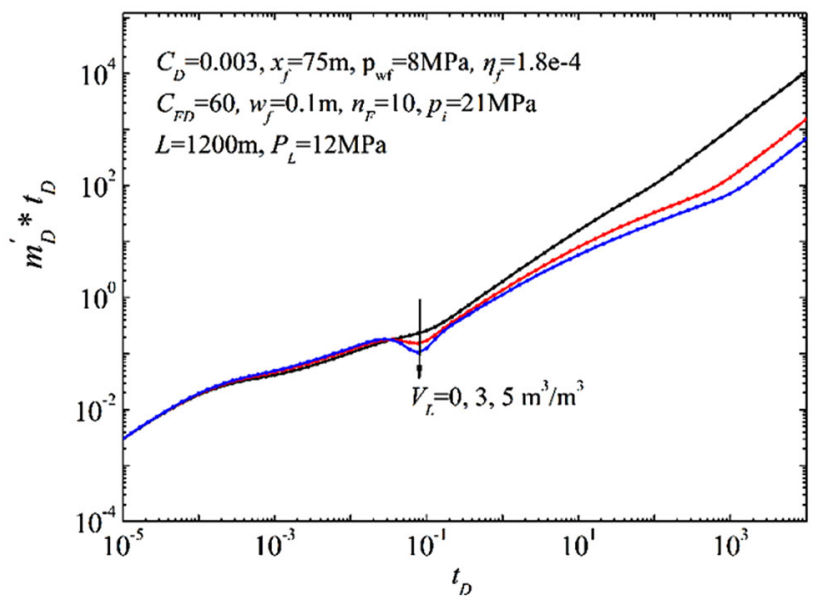

Fig. 7 Effect of Langmuir volume on pressure transient responses

Figure 8 reflects the effect of SRV on pressure transient responses when the well produces at a constant production rate. The values of relevant parameters are listed in Table 1 , and set $x_{1}=20,30,40, y_{1}=25,35$, 40. Larger stimulated reservoir volume means more space of free gas and longer duration of linear flow, which causes the appearance of the adsorption and desorption process later. Therefore, the larger stimulated reservoir volume leads to the deeper concave. Under the same condition, when the matrix area decreases, the effect of adsorption and desorption process becomes weak accordingly.

\section{Analysis of production performance}

The linear flow region is affected by fracture half-length, stimulated volume, and the permeability in different regions. The log-log pressure and pressure derivative plots were used to identify flow regimes, while the linear flow analysis (rate-normalized pressure vs. square root of time) 
was used to obtain the parameters by producing data of wells (Kurtoglu et al. 2013). The time tef was defined to present the over time of formation linear flow, and the effects of different parameters on linear flow analysis were studied.

Figure 9 shows the well rate-normalized pressure at different bottom-hole pressures. The values of the bottomhole pressure are set $p_{\mathrm{wf}}=4,8,12,16 \mathrm{MPa}$. For multistage fractured horizontal well in shale gas reservoirs, the free gas in fractures and inorganic matrix pores is produced first. Then, the adsorbed gas on the organic matrix desorbs into the fractures gradually. During the early stage, the production is affected mainly by the formation of linear flow. When the pressure transmits to the boundary, there is a sharp increase on the curve. So, the time tef of different bottom-hole pressure is absolutely different. The lower flowing bottom-hole pressure is, the shorter tef is, because

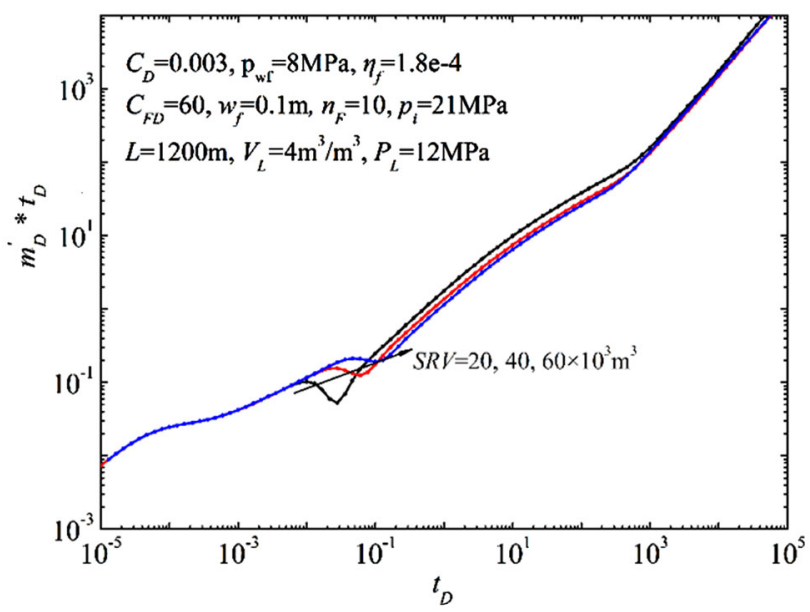

Fig. 8 Effect of SRV on pressure transient responses

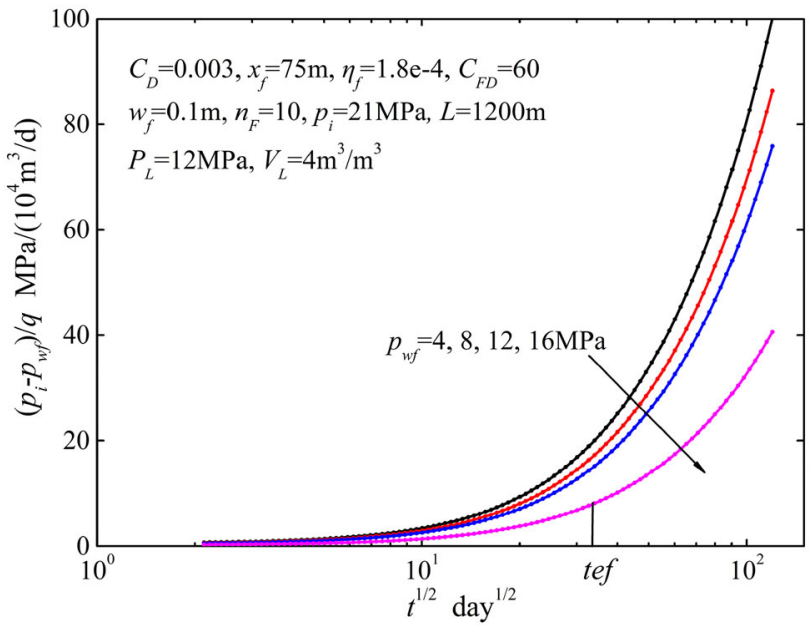

Fig. 9 Square root of time plots exhibiting different bottom-hole pressure the larger producing pressure drop enhances the fluid flow in formation.

Figure 10 shows the effect of Langmuir volumes on the well rate-normalized pressure curves when $V_{\mathrm{L}}=0,3,5$. The Langmuir volume powerfully influences on the adsorption and desorption process. Therefore, the production curve without taking adsorption effect into consideration $\left(V_{\mathrm{L}}=0\right)$ sits on the top compared with other curves considering that. This case is because desorption from matrix can slow down the reduction in production. In addition, the increase in the Langmuir volume leads to the larger production and longer time of formation linear flow, so it is necessary to figure out the influences of adsorption and desorption on production forecast.

Figure 11 shows the effect of stimulated reservoir volume on the well rate-normalized pressure curves with variation in the stimulated reservoir volume, when,

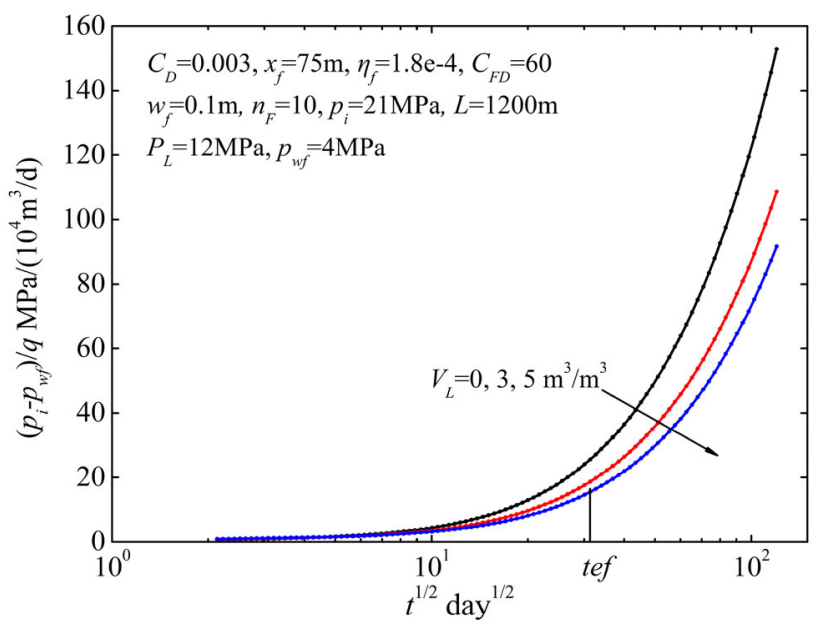

Fig. 10 Square root of time plots exhibiting different Langmuir volumes

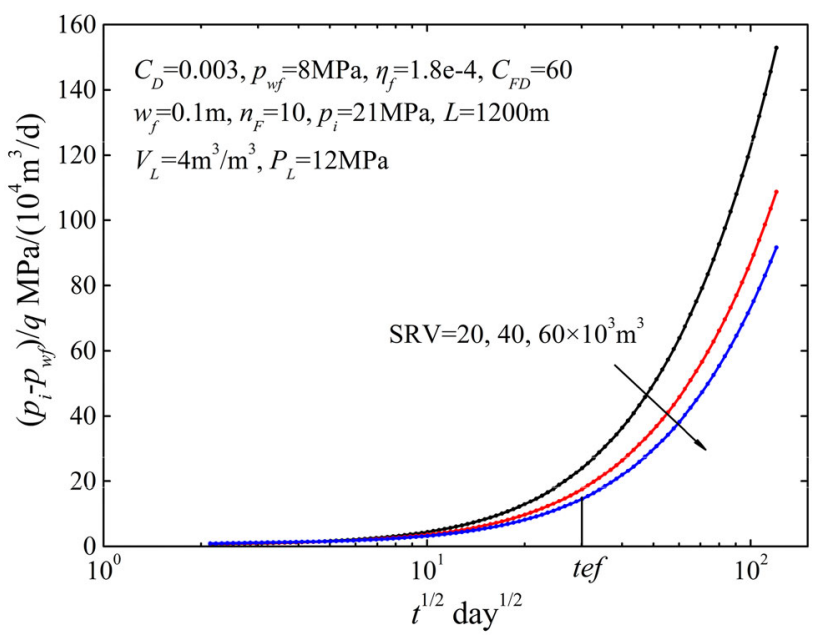

Fig. 11 Square root of time plots exhibiting different SRV 
$x_{1}=20,30,40, y_{1}=35,35,40$. Fracturing stimulation can create large permeability fracture regions around the hydraulic fractures with high conductivity and decreases the flow resistance in formation; thus, lager stimulated reservoir volume results in higher production rate and longer time of formation linear flow. In the actual production, expending the scale of stimulated regions is the effective method to improve the development of shale gas reservoirs.

\section{Conclusions}

Based on the limited stimulation region, in this paper the modified five-region model was built considering the stimulated reservoir volume and the adsorption and desorption process for multistage fractured horizontal well in shale gas reservoirs. The bottom-hole pressure solution and the production solution were obtained. Pressure transient and rate transient responses were analyzed in this paper. And some conclusions can be drawn.

1. Mathematical models for conventional reservoirs cannot be used to represent the fluid flow in unconventional reservoirs. The coupling modified mathematical model could describe the comprehensive gas flow in both multistage fractured horizontal well and formation. Specifically, the stimulated reservoir volume and the shale gas properties are introduced into the model in this paper compared to the Eclipse simulator. The transient pressure curves are divided into eight regimes, and these regimes change with different formation properties and MFHW properties.

2. There are two occurrence modes for shale gas in shale formation, adsorbed gas mainly existing in matrix and free gas mainly existing in natural fractures. The comparison of the composite model predictions using the field data and actual production data demonstrates that the five-region model considering the stimulated reservoir volume and adsorption and desorption process is able to describe the gas flow of multistage fractured horizontal well in shale gas reservoir. In addition, the simulation results of Eclipse simulator without the adsorption and desorption process show that desorption of the adsorbed gas in shale formation matrix should not be neglected in mathematical models.

3. Besides adsorption and desorption process, wellbore storage coefficient, SRV, and bottom-hole pressure have significant effects on the well pressure and production performance of multistage fractured horizontal well in shale gas reservoirs. The wellbore storage coefficient mainly affects the early production stage. The SRV has significant effects on the late flow stage in the transient pressure and production rate curves. Larger SRV leads to lower transient pressure at constant production and longer tef at constant flowing pressure for the same reason. That means the development of shale gas reservoirs depends on the stimulated reservoir volume. Large Langmuir volume means the adsorption and desorption abilities are strong, which is important to maintain stable gas production rate in late flow stage. The bottom-hole pressure is also a significant parameter for developing the shale gas reservoirs. In view of the simplification of this model, some further work is required to make the model approximate to the practice.

Acknowledgments This work was supported by the National Basic Research Program of China (2014CB239103) and the Natural Science Foundation of Shandong Province, China (ZR2014EL014).

Open Access This article is distributed under the terms of the Creative Commons Attribution 4.0 International License (http:// creativecommons.org/licenses/by/4.0/), which permits unrestricted use, distribution, and reproduction in any medium, provided you give appropriate credit to the original author(s) and the source, provide a link to the Creative Commons license, and indicate if changes were made.

\section{Appendix: Derivation of the multi-linear flow model}

Based on the linear flow assumptions, the multi-linear flow model is established in the rectangular coordinate system as follows.

- Liner flow in matrix

Considering the absorption and desorption process in these regions, mass conservation equation is

$-\frac{\partial}{\partial x}\left(\rho_{\mathrm{gm}} v_{\mathrm{m}}\right)=\frac{\partial}{\partial t}\left(\phi_{\mathrm{m}} \rho_{\mathrm{gm}}+\rho_{\mathrm{gsc}} V_{\mathrm{E}}\right)$

According to the Darcy's law, the flow velocity in porous media can be expressed as

$v=-\frac{k}{\mu} \frac{\partial p}{\partial x}$.

For the real gas, the gas density is given by

$\rho_{\mathrm{g}}=\frac{p}{Z} \frac{M}{R T}$.

The relationship between the gas concentration and the pressure can be described by the Langmuir equation as

$V_{\mathrm{E}}=\frac{V_{\mathrm{L}} p}{p+p_{\mathrm{L}}}$. 
The total compressibility coefficient considering the effect of adsorption and desorption process (Gao et al. 1994) is defined as

$c_{\mathrm{tm}}=c_{\mathrm{gm}}+\frac{\rho_{\mathrm{gsc}} V_{\mathrm{L}} p_{\mathrm{L}}}{\phi_{\mathrm{m}} \frac{M p}{Z R T}\left(p+p_{\mathrm{L}}\right)^{2}}$,

where $c_{\mathrm{gm}}=\frac{1}{p}-\frac{1}{Z} \frac{\mathrm{d} Z}{\mathrm{~d}_{p}}=c_{\mathrm{gm}}\left(p_{\mathrm{i}}\right)=c_{\mathrm{gmi}}$.

Then, substituting Eqs. (16)-(20) into the mass conservation equation Eq. (16), we can obtain

$-\frac{\partial}{\partial x}\left(-\frac{p}{Z} \frac{M}{R T} \frac{k}{\mu} \frac{\partial p}{\partial x}\right)=\frac{\partial}{\partial t}\left(\phi_{\mathrm{m}} \frac{p}{Z} \frac{M}{R T}+\rho_{\mathrm{gsc}} \frac{V_{\mathrm{L}} p}{p+p_{\mathrm{L}}}\right)$,

$$
\begin{aligned}
& \frac{M k}{R T} \frac{\partial}{\partial x}\left(\frac{p}{Z \mu} \frac{\partial p}{\partial x}\right)= \frac{\phi_{\mathrm{m}} M}{R T}\left(\frac{1}{Z}-\frac{p}{Z^{2}} \frac{\partial Z}{\partial p}\right) \frac{\partial p}{\partial t} \\
&+\rho_{\mathrm{gsc}}\left[\frac{V_{\mathrm{L}}}{p+p_{\mathrm{L}}}-\frac{V_{\mathrm{L}} p}{\left(p+p_{\mathrm{L}}\right)^{2}}\right] \frac{\partial p}{\partial t}, \\
& k \frac{\partial}{\partial x}\left(\frac{2 p}{Z \mu} \frac{\partial p}{\partial x}\right)=\phi_{\mathrm{m}} \mu\left\{\left(\frac{1}{p}-\frac{1}{Z} \frac{\partial Z}{\partial p}\right)+\frac{\rho_{\mathrm{gsc}} V_{\mathrm{L}} p_{\mathrm{L}}}{\phi_{\mathrm{m}} \frac{M_{p}}{Z R T}\left(p+p_{\mathrm{L}}\right)^{2}}\right\} \frac{2 p}{Z \mu} \frac{\partial p}{\partial t} .
\end{aligned}
$$

Then, Eq. (23) becomes

$$
\begin{aligned}
& \frac{\partial^{2} m}{\partial x^{2}}=\frac{\phi_{\mathrm{m}} \mu c_{\mathrm{tm}}}{k} \frac{\partial m}{\partial t}, \\
& \frac{\partial^{2} m}{\partial x^{2}}=\frac{1}{\eta} \frac{\partial m}{\partial t},
\end{aligned}
$$

where $\eta$ is the pressure transitivity, defined as $\eta=\frac{k}{\phi_{\mathrm{m}} c_{\mathrm{m}} \mu}$.

Then, derive the five-linear flow solution in terms of dimensionless variables for simple calculation. Define dimensionless parameters,

$$
\begin{array}{r}
m_{n \mathrm{D}}=\frac{\pi k_{\mathrm{f}} h T_{\mathrm{sc}}\left(m_{\mathrm{n}}-m_{\mathrm{i}}\right)}{q_{\mathrm{sc}} p_{\mathrm{sc}} T}, \quad n=1,2,3,4, \quad t_{\mathrm{D}}=\frac{k_{\mathrm{f}} t}{\phi_{\mathrm{f}} c_{\mathrm{tf}} \mu x_{\mathrm{f}}^{2}}, \\
x_{\mathrm{D}}=\frac{x}{x_{\mathrm{f}}}, \quad y_{\mathrm{D}}=\frac{y}{x_{\mathrm{f}}}, \quad \eta_{\mathrm{D}}=\frac{\eta}{\eta_{\mathrm{f}}}, \quad \eta_{\mathrm{f}}=\frac{k_{\mathrm{f}}}{\phi_{\mathrm{f}} c_{\mathrm{tf}} \mu} .
\end{array}
$$

The dimensionless form of flow equation is

$\frac{q_{\mathrm{sc}} p_{\mathrm{sc}} T}{\pi k h T_{\mathrm{sc}}} \frac{1}{x_{f}^{2}} \frac{\partial^{2} m_{\mathrm{D}}}{\partial x_{\mathrm{D}}^{2}}=\frac{1}{\eta} \frac{q_{\mathrm{sc}} p_{\mathrm{sc}} T}{\pi k h T_{\mathrm{sc}}} \frac{k_{f}}{\phi_{\mathrm{f}} c_{\mathrm{tf}} \mu x_{\mathrm{f}}^{2}} \frac{\partial m_{\mathrm{D}}}{\partial t_{\mathrm{D}}}$.

$\frac{\partial^{2} m_{\mathrm{D}}}{\partial x_{\mathrm{D}}^{2}}=\frac{1}{\eta_{\mathrm{D}}} \frac{\partial m_{\mathrm{D}}}{\partial t_{\mathrm{D}}}$.

Taking the region 4 for example, with closed reservoir, dimensionless initial condition and boundary conditions are as follows:

Initial condition is

$m_{\mathrm{D}}(0, y)=0$.
Outer boundary condition (closed boundary) is

$\left.\frac{\partial m_{4 \mathrm{D}}}{\partial y_{\mathrm{D}}}\right|_{y_{\mathrm{D}}=y_{2 \mathrm{D}}}=0$.

Inner boundary condition (pressure continuity) is

$\left.m_{4 \mathrm{D}}\right|_{y=y_{1 \mathrm{D}}}=\left.m_{2 \mathrm{D}}\right|_{y=y_{1 \mathrm{D}}}$.

Using Laplace transform, combining with the initial condition and boundary conditions, the mathematical model of linear flow in region 4 is

$$
\left\{\begin{array}{c}
\frac{\partial^{2} \overline{m_{4 \mathrm{D}}}}{\partial y_{\mathrm{D}}^{2}}-\frac{2}{\eta_{\mathrm{D}}} \overline{m_{4 \mathrm{D}}}=0 \\
\left.\frac{\partial \overline{m_{4 \mathrm{D}}}}{\partial y_{\mathrm{D}}}\right|_{y_{\mathrm{D}}=y_{2 \mathrm{D}}}=0 \\
\left.\overline{m_{4 \mathrm{D}} \mathrm{D}}\right|_{y_{\mathrm{D}}=y_{\mathrm{I}}}=\left.\overline{m_{2 \mathrm{D}}}\right|_{y_{\mathrm{D}}=y_{1 \mathrm{D}}}
\end{array} .\right.
$$

The solution of pressure in Laplace space is derived

$$
\overline{m_{4 \mathrm{D}}}=\left.\overline{m_{2 \mathrm{D}}}\right|_{y_{\mathrm{D}}=y_{1 \mathrm{D}}} \cdot \frac{\cosh \left[\sqrt{r}\left(y_{2 \mathrm{D}}-y_{\mathrm{D}}\right)\right]}{\cosh \left[\sqrt{r}\left(y_{1 \mathrm{D}}-y_{2 \mathrm{D}}\right)\right]} .
$$

Due to the similar properties of region 3 with region 4 , the mathematical model of region 3 could be expressed as

$$
\left\{\begin{array}{c}
\frac{\partial^{2} \overline{m_{3 \mathrm{D}}}}{\partial y_{\mathrm{D}}^{2}}-\frac{2}{\eta_{\mathrm{D}}} \overline{m_{3 \mathrm{D}}}=0 \\
\left.\frac{\partial \overline{m_{3 \mathrm{D}}}}{\partial y_{\mathrm{D}}}\right|_{y_{\mathrm{D}}=y_{2 \mathrm{D}}}=0 \\
\left.\overline{m_{3 \mathrm{D}}}\right|_{y_{\mathrm{D}}=y_{1 \mathrm{D}}}=\left.\overline{m_{1 \mathrm{D}}}\right|_{y_{\mathrm{D}}=y_{\mathrm{I}}}
\end{array} .\right.
$$

The solution of Eq. (33) could be obtained

$\overline{m_{3 \mathrm{D}}}=\left.\overline{m_{1 \mathrm{D}}}\right|_{y_{\mathrm{D}}=y_{1 \mathrm{D}}} \cdot \frac{\cosh \left[\sqrt{r}\left(y_{2 \mathrm{D}}-y_{\mathrm{D}}\right)\right]}{\cosh \left[\sqrt{r}\left(y_{1 \mathrm{D}}-y_{2 \mathrm{D}}\right)\right]}$,

where $r=\frac{s}{\eta_{\mathrm{D}}}$.

In region 2 , linear flow along $x$-coordinate and adsorption-desorption process as well as flux from region 4 are taken into account. The governing equation of region 2 in rectangular coordinate system is

$\frac{\partial^{2} m}{\partial x^{2}}+\frac{\partial^{2} m}{\partial y^{2}}=\frac{1}{\eta} \frac{\partial m}{\partial t}$.

We integrate all the terms in the equation from 0 to $y_{1}$ with respect to turn the equation into a $1 \mathrm{D}$ form. Then, the diffusion equation is

$y_{1} \frac{\partial^{2} m_{2}}{\partial x^{2}}+\left.\frac{\partial^{2} m_{2}}{\partial y^{2}}\right|_{y=y_{1}}=y_{1} \frac{1}{\eta} \frac{\partial m_{2}}{\partial t}$.

Flow from region 4 to region 2 is continuous; therefore,

$\left.k_{2} \frac{\partial m_{2}}{\partial y}\right|_{y=y_{1}}=\left.k_{4} \frac{\partial m_{4}}{\partial y}\right|_{y=y_{1}}$.

Then, the mathematical model of region 2 under Laplace space is 


$$
\left\{\begin{array}{c}
\frac{\partial^{2} \overline{m_{2 \mathrm{D}}}}{\partial x_{\mathrm{D}}^{2}}+\left.\frac{1}{y_{1 \mathrm{D}}} \frac{k_{4}}{k_{2}} \frac{\partial \overline{m_{4 \mathrm{D}}}}{\partial y_{\mathrm{D}}}\right|_{y_{\mathrm{D}}=y_{1 \mathrm{D}}}=\frac{s}{\eta_{2 \mathrm{D}}} \overline{m_{2 \mathrm{D}}} \\
\left.\frac{\partial \overline{m_{2 \mathrm{D}}}}{\partial x_{\mathrm{D}}}\right|_{x_{\mathrm{D}}=x_{2 \mathrm{D}}}=0 \\
\left.\overline{m_{2 \mathrm{D}} \mid}\right|_{x_{\mathrm{D}}=x_{1 \mathrm{D}}}=\left.\overline{m_{1 \mathrm{D}}}\right|_{x_{\mathrm{D}}=x_{1 \mathrm{D}}}
\end{array} .\right.
$$

The solution of flow model of region 2 in Laplace space is

$\overline{m_{2 \mathrm{D}}}=\overline{m_{1 \mathrm{D}}} x_{\mathrm{D}}=x_{1 \mathrm{D}} \cdot \frac{\cosh \left[\sqrt{a}\left(x_{\mathrm{D}}-x_{2 \mathrm{D}}\right)\right]}{\cosh \left[\sqrt{a}\left(x_{1 \mathrm{D}}-x_{2 \mathrm{D}}\right)\right]}$,

where $a=\frac{1}{y_{1 \mathrm{D}}} \frac{k_{4}}{k_{2}} \frac{\sqrt{r} \sinh \left[\sqrt{r}\left(y_{2 \mathrm{D}}-y_{1 \mathrm{D}}\right)\right]}{\cosh \left[\sqrt{r}\left(y_{1 \mathrm{D}}-y_{2 \mathrm{D}}\right)\right]}-\frac{s}{\eta_{2 \mathrm{D}}}$.

\section{- Linear flow in stimulated region}

The stimulated region (region 1) has high conductivity. In this paper, the main flow regime is linear flow along $x$ coordinate as well as flux from region 2 and region 3 . The mass conservation equation is

$\frac{\partial^{2} m_{1}}{\partial x^{2}}+\frac{\partial^{2} m_{1}}{\partial y^{2}}=\frac{1}{\eta_{1}} \frac{\partial m_{1}}{\partial t}$.

Use the same method as Eq. (35) to convert Eq. (39) to 1D equation:

$y_{1} \frac{\partial^{2} m_{1}}{\partial x^{2}}+\left.\frac{\partial m_{1}}{\partial y}\right|_{y=y_{1}}=y_{1} \frac{1}{\eta_{1}} \frac{\partial m_{1}}{\partial t}$.

Region 1 is located between region 2 and fracture region and adjacent region 3 , so flow rate and pressure continuous conditions related to this region are considered. The model in Laplace space is:

$$
\left\{\begin{array}{l}
\frac{\partial^{2} \overline{m_{1 \mathrm{D}}}}{\partial x_{\mathrm{D}}^{2}}+\left.\frac{1}{y_{1 \mathrm{D}}} \frac{k_{3}}{k_{f 1}} \frac{\partial \overline{m_{3 \mathrm{D}}}}{\partial y_{\mathrm{D}}}\right|_{y_{\mathrm{D}}=y_{1 \mathrm{D}}}=\frac{s}{\eta_{1 \mathrm{D}}} \overline{m_{2 \mathrm{D}}} \\
\left.k_{2} \frac{\partial \overline{m_{2 \mathrm{D}}}}{\partial x_{\mathrm{D}}}\right|_{x_{\mathrm{D}}=x_{1 \mathrm{D}}}=\left.k_{f 1} \frac{\partial \overline{m_{1}}}{\partial x_{\mathrm{D}}}\right|_{x_{\mathrm{D}}=x_{1 \mathrm{D}}} \\
\left.\overline{m_{1 \mathrm{D}}}\right|_{x_{\mathrm{D}}=w_{\mathrm{fD}} / 2}=\left.\overline{m_{\mathrm{fD}}}\right|_{x_{\mathrm{D}}=w_{\mathrm{fD}} / 2}
\end{array} .\right.
$$

In sum, the solution of the model of stimulated region in Laplace space is

$\overline{m_{1 \mathrm{D}}}=\left.\mathrm{e}^{\sqrt{b} \frac{w_{\mathrm{D}}}{2}} m_{\mathrm{fD}}\right|_{x_{\mathrm{D}}=\frac{w_{\mathrm{D}}}{2}}\left[\frac{(f+1) \mathrm{e}^{\sqrt{b} x_{\mathrm{D}}}+(1-f) \mathrm{e}^{2 \sqrt{b} x_{\mathrm{ID}}-\sqrt{b} x_{\mathrm{D}}}}{\mathrm{e}^{2 \sqrt{b} x_{\mathrm{D}}}+\mathrm{e}^{2 \sqrt{b} \frac{w_{\mathrm{D}}}{2}}-\left(\mathrm{e}^{2 \sqrt{b} x_{\mathrm{ID}}}-\mathrm{e}^{2 \sqrt{b} \frac{w_{\mathrm{D}}}{2}}\right) f}\right]$,

where

$f=\frac{\sqrt{a} k_{2}}{\sqrt{b} k_{f 1}} \frac{\sinh \left[\sqrt{a}\left(x_{1 \mathrm{D}}-x_{2 \mathrm{D}}\right)\right]}{\cosh \left[\sqrt{a}\left(x_{1 \mathrm{D}}-x_{2 \mathrm{D}}\right)\right]}$.

$$
b=\frac{1}{y_{1 \mathrm{D}}} \frac{k_{3}}{k_{f 1}} \frac{\sqrt{r} \sinh \left[\sqrt{r}\left(y_{2 \mathrm{D}}-y_{1 \mathrm{D}}\right)\right]}{\cosh \left[\sqrt{r}\left(y_{1 \mathrm{D}}-y_{2 \mathrm{D}}\right)\right]}+\frac{s}{\eta_{1 \mathrm{D}}},
$$

- Linear flow in hydraulic fracture region

In the hydraulic fracture region, linear flow is dominant. With flux from stimulated region, the mass conservation equation is: $\frac{\partial^{2} m_{\mathrm{f}}}{\partial y^{2}}+\frac{\partial^{2} m_{\mathrm{f}}}{\partial x^{2}}=\frac{1}{\eta_{f}} \frac{\partial m_{\mathrm{f}}}{\partial t}$.

With the same method with Eq. (36), assuming the pressure in fracture region is independent of $x$-coordinate, we integrate all the terms from 0 to $w_{\mathrm{f}} / 2$.

$\frac{w_{\mathrm{f}}}{2} \frac{\partial^{2} m_{\mathrm{f}}}{\partial y^{2}}+\left.\frac{\partial m_{\mathrm{f}}}{\partial x}\right|_{x=w_{\mathrm{f}} / 2}-\left.\frac{\partial m_{\mathrm{f}}}{\partial x}\right|_{x=0}=\frac{w_{\mathrm{f}}}{2} \frac{1}{\eta_{\mathrm{f}}} \frac{\partial m_{\mathrm{f}}}{\partial t}$.

Through Laplace transformation, we can get the model set with no-flow tip of the fracture and constant production rate at the bottom hole:

$$
\left\{\begin{array}{l}
\frac{\partial^{2} \overline{m_{\mathrm{fD}}}}{\partial y_{\mathrm{D}}^{2}}+\left.\frac{2}{C_{\mathrm{FD}}} \frac{\partial \overline{m_{\mathrm{fD}}}}{\partial y_{\mathrm{D}}}\right|_{x_{\mathrm{D}}=w_{\mathrm{fD}} / 2}=s \overline{m_{\mathrm{fD}}} \\
\left.\frac{\partial \overline{m_{\mathrm{fD}}}}{\partial y_{\mathrm{D}}}\right|_{y_{\mathrm{D}}=y_{\mathrm{D}}}=0 \\
\left.\frac{\partial \overline{m_{\mathrm{fD}}}}{\partial y_{\mathrm{D}}}\right|_{y_{\mathrm{D}}=0}=-\frac{\pi}{s C_{\mathrm{FD}}}
\end{array} .\right.
$$

where $C_{\mathrm{FD}}=\frac{k_{2} w_{\mathrm{FD}}}{k_{\mathrm{f}}}$.

From the analytical solution of model of stimulated region, the pressure is expressed as follows:

$\bar{m}_{\mathrm{fD}}=\frac{\pi}{\sqrt{g} s C_{\mathrm{FD}}} \frac{\cosh \left[\sqrt{g}\left(y_{\mathrm{D}}-y_{1 \mathrm{D}}\right)\right]}{\sinh \left[-\sqrt{g} y_{1 \mathrm{D}}\right]}$,

where $g=\frac{2}{C_{\mathrm{FD}}} \sqrt{b}\left[\frac{(1-f) \mathrm{e}^{2 \sqrt{b} x_{\mathrm{D}}}-(1+f) \mathrm{e}^{2 \sqrt{b} w_{\mathrm{F}}}}{\mathrm{e}^{2 \sqrt{b} x_{1 \mathrm{D}}}+\mathrm{e}^{2 \sqrt{b} \frac{\mathrm{FD}}{2}}-\left(\mathrm{e}^{2 \sqrt{b} x_{\mathrm{D}}}-\mathrm{e}^{2 \sqrt{b} \frac{w_{\mathrm{F}}}{2}}\right) f}\right]$.

\section{References}

Agboada DK, Ahmadi M (2013) Production decline and numerical simulation model analysis of the eagle ford shale play. In: SPE western regional and AAPG pacific section meeting joint technical conference. Society of Petroleum Engineers, Monterey

Ali Daneshy A (2003) Off-balance growth: a new concept in hydraulic fracturing. J Petrol Technol 55(04):78-85

Brown M, Ozkan E, Raghavan R, Kazemi H (2009) Practical solutions for pressure transient responses of fractured horizontal wells in unconventional reservoirs. In: SPE annual technical conference and exhibition. Society of Petroleum Engineers, New Orleans

Brown M, Ozkan E, Raghavan R, Kazemi H (2011) Practical solutions for pressure-transient responses of fractured horizontal wells in unconventional shale reservoirs. SPE Reservoir Eval Eng 14(06):663-676

Bumb AC, McKee CR (1988) Gas-well testing in the presence of desorption for coalbed methane and Devonian Shale. SPE Form Eval 3(01):179-185

Clarkson CR (2013) Production data analysis of unconventional gas wells: review of theory and best practices. Int $\mathrm{J}$ Coal Geol 109-110:101-146

Dehghanpour H, Shirdel M (2011) A triple porosity model for shale gas reservoirs. In: Canadian unconventional resources conference. Society of Petroleum Engineers, Alberta 
Everdingen AF, Hurst W (1949) The application of the Laplace transformation to flow problems in reservoirs. J Petrol Technol 1(12):305-324

Ezulike DO, Dehghanpour H (2014) A model for simultaneous matrix depletion into natural and hydraulic fracture networks. J Nat Gas Sci Eng 16:57-69

Gao C, Lee JW, Spivey JP, Semmelbeck ME (1994) Modeling multilayer gas reservoirs including sorption effects. In: SPE eastern regional meeting. Society of Petroleum Engineers, Charleston

Gerami S, Pooladi-Darvish M, Morad K, Mattar L (2008) Type curves for dry CBM reservoirs with equilibrium desorption. J Can Pet Technol 47(07)

Guo JJ, Zhang LH, Wang HT, Feng GQ (2012) Pressure transient analysis for multi-stage fractured horizontal wells in shale gas reservoirs. Transp Porous Media 93(3):635-653

Juan C, Aquiles R (2012) Unconventional reservoirs: basic petrophysical concepts for shale gas. In: SPE/EAGE European unconventional resources conference and exhibition. Society of Petroleum Engineers, Vienna

Ketineni S P, Ertekin T (2012) Analysis of production decline characteristics of a multistage hydraulically fractured horizontal well in a naturally fractured reservoir. In: SPE eastern regional meeting. Society of Petroleum Engineers, Lexington

Kurtoglu B, Ramirez B, Kazemi H (2013) Modeling production performance of an abnormally high pressure unconventional shale reservoir. In: Unconventional Resources Technology Conference, Denver

Mayerhofer MJ, Lolon EP, Youngblood JE, Heinze JR (2006) Integration of micro-seismic fracture mapping results with numerical fracture network production modeling in the Barnett shale. In: SPE annual technical conference and exhibition (ATCE'06). Society of Petroleum Engineers, San Antonio

Mayerhofer MJ, Lolon EP, Rightmire C, Walser D, Cipolla CL, Warplnskl NR (2010) What is stimulated reservoir volume? SPE Prod Oper 25(01):89-98

Mediros F, Ozkan E, Kazemi H (2007) Productivity and drainage area of fracture horizontal wells in tight gas reservoirs. In: Rocky mountain oil and gas technology symposium. Society of Petroleum Engineers, Denver

Meyer BR, Bazan LW (2011) A discrete fracture network model for hydraulically induced fractures: theory, parametric and case studies. In: SPE hydraulic fracturing technology conference. Society of Petroleum Engineers, Woodlands

Ozkan E, Raghavan R, Apaydin O (2010) Modeling of fluid transfer from shale matrix to fracture network. In: SPE annual technical conference and exhibition. Society of Petroleum Engineers, Florence

Ross DJK, Bustin RM (2007) Impact of mass balance calculations on adsorption capacities in microporous shale gas reservoirs. Fuel 86(26):2696-2706

Sang Y, Chen H, Yang SL, Guo XZ, Zhou CS, Fang BH, Zhou F, Yang JK (2014) A new mathematical model considering adsorption and desorption process for productivity prediction of volume fractured horizontal wells in shale gas reservoirs. J Nat Gas Sci Eng 19:228-236

Stalgorova E, Mattar L (2012a) Analytical model for history matching and forecasting production in multifrac composite systems. In: SPE Canadian unconventional resources conference (CURC'12). Society of Petroleum Engineers, pp 450-466

Stalgorova E, Mattar L (2012b) Practical analytical model to simulate production of horizontal wells with branch fractures. In: SPE Canadian unconventional resources conference. Society of Petroleum Engineers, Calgary

Stehfest H (1970) Algorithm 368: numerical inversion of Laplace transforms. Commun ACM 13(1):47-49

Su YL, Zhang Q, Wang WD, Sheng GL (2015) Performance analysis of a composite dual-porosity model in multi-scale fractured shale reservoir. J Nat Gas Sci Eng 26:1107-1118

Suliman B, Meek R, Hull R, Bello H, Richmond P (2013) Variable stimulated reservoir volume (SRV) simulation: eagle ford shale case study. In: SPE unconventional resources conference. Society of Petroleum Engineers, Denver

Wang H, Liao X, Lu N et al (2014) A study on development effect of horizontal well with SRV in unconventional tight oil reservoir. J Energy Inst 87(2):114-120

Warren JE, Root PJ (1963) The behavior of naturally fractured reservoirs. Soc Petrol Eng J 3(03):245-255

Zhang J, Huang SJ, Cheng LS, Liu HJ, Yang Y, Xue YC (2015) Effect of flow mechanism with multi-nonlinearity on production of shale gas. J Nat Gas Sci Eng 24(2015):291-301. doi:10.1016/ j.jngse.2015.03.043 